\title{
Development of a Data Acquisition System for the Testing and Verification of Electrical Power Quality Meters
}

\author{
Milan Simic ${ }^{\dagger}$, Dragan Denic ${ }^{*}$, Dragan Zivanovic ${ }^{*}$, Dimitar Taskovski ${ }^{* *}$, and Vladimir Dimcev ${ }^{* *}$ \\ ${ }^{\dagger *}$ University of Nis, Faculty of Electronic Engineering, Nis, Serbia \\ ${ }^{* *}$ Ss. Cyril and Methodius University in Skopje, Faculty of Electrical Engineering and Information Technologies, \\ Skopje, Macedonia
}

\begin{abstract}
This paper presents the development of a software supported acquisition system for metrological verification and testing of the equipment for monitoring and analysis of the basic electrical power quality parameters. The described procedure consists of two functionally connected segments. The first segment involves generation of the reference three-phase voltage signals, including the possibility of simulation of the various power quality disturbances, typical for electrical power distribution networks. The second part of this procedure includes the real-time recording of power quality disturbances in three-phase distribution networks. The procedure is functionally supported by the virtual instrumentation concept, including a software application developed in LabVIEW environment and data acquisition boards NI 6713 and NI 9215A. The software support of this system performs graphical presentation of the previously generated and recorded signal waveforms. A number of the control functions and buttons, implemented on the virtual instrument front panels, are provided to adjust the basic signal acquisition, generation and recording parameters.
\end{abstract}

Key words: Acquisition system, Metrological verification, Power quality meters, Virtual instrumentation software

\section{INTRODUCTION}

Various distribution network disturbances and problems in the form of voltage amplitude fluctuations and the presence of the high-order signal harmonic components are the primary reasons for decreases in the electrical power quality (PQ) level. Degradation of the basic quality parameters directly causes decreases in the total energy efficiency in the process of electrical power production, distribution to the customers and consumption. Significant limitations on the natural energy resources necessary for electrical power production and widespread inclusion of alternative energy sources have resulted in increased concern over power quality problems in recent years. The automated electronic

Manuscript received Feb. 15, 2012; revised Jul. 2, 2012

Recommended for publication by Associate Editor Kyeon Hur.

${ }^{\dagger}$ Corresponding Author: milan.simic@elfak.ni.ac.rs

Tel: +381-18-529-202, Fax: +381-18-588-399, University of Nis

*University of Nis, Faculty of Electronic Engineering, Serbia

${ }^{* *}$ Ss. Cyril and Methodius University in Skopje, Faculty of Electrical

Engineering and Information Technologies, Macedonia equipment used in various domestic, commercial and industrial facilities, are highly sensitive to possible PQ degradations and network disturbances. In order to reduce the possibilities for disturbances and to prevent potential failures of customer equipment and devices, power distribution companies obligated to perform continuous monitoring of power distribution networks, including measurement and analysis of the basic power quality (PQ) parameters and disturbances, as prescribed by the relevant international quality standards [1], [2].

Generally, due to the importance and complexity of this topic, the detailed analysis and resolving of PQ problems demand a combination of the various activities, such as: digital signal processing (DSP) techniques, power engineering and software engineering methods, supported by advanced programming tools and sophisticated measurement equipment. Important and valid information about the quality level of distribution networks can be provided only by measurements of the basic quality parameters, including detailed processing of the obtained measurement results [3], 
TABLE I

BASIC REQUIREMENTS OF THE PQ STANDARD EN 50160

\begin{tabular}{||l|c|c|c||}
\hline $\begin{array}{l}\text { PQ } \\
\text { disturbances }\end{array}$ & $\begin{array}{c}\text { Acceptable } \\
\text { limits }\end{array}$ & $\begin{array}{c}\text { Measurem. } \\
\text { intervals }\end{array}$ & $\begin{array}{c}\text { Monitor. } \\
\text { periods }\end{array}$ \\
\hline $\begin{array}{l}\text { frequency } \\
\text { variations }\end{array}$ & $50 \mathrm{~Hz} \pm 1 \%$ & $10 \mathrm{~s}$ & 1 week \\
\hline $\begin{array}{l}\text { RMS voltage } \\
\text { variations }\end{array}$ & $230 \mathrm{~V} \pm 10 \%$ & $10 \mathrm{~min}$ & 1 week \\
\hline voltage sags & $\begin{array}{c}10 \text { to } 1000 \\
\text { times per year }\end{array}$ & $10 \mathrm{~ms}$ & 1 year \\
\hline $\begin{array}{l}\text { short voltage } \\
\text { interruptions }\end{array}$ & $\begin{array}{c}10 \text { to } 100 \\
\text { times per year }\end{array}$ & $10 \mathrm{~ms}$ & 1 year \\
\hline $\begin{array}{l}\text { long voltage } \\
\text { interruptions }\end{array}$ & $\begin{array}{c}10 \text { to } 50 \\
\text { times per year }\end{array}$ & $10 \mathrm{~ms}$ & 1 year \\
\hline $\begin{array}{l}\text { temporary } \\
\text { overvoltages }\end{array}$ & $\begin{array}{c}\text { mostly } \\
<1.5 \mathrm{kV}\end{array}$ & $10 \mathrm{~ms}$ & - \\
\hline unbalance & $2 \%$ to $3 \%$ & $10 \mathrm{~min}$ & 1 week \\
\hline harmonics & $8 \%$ (THD) & $10 \mathrm{~min}$ & 1 week \\
\hline
\end{tabular}

[4]. The nominal reference values of the quality parameters, acceptable tolerances and measurement intervals, are defined by relevant international documents and quality standards. The European PQ standard EN 50160, developed by CENELEC, European Committee for Electrotechnical Standardization, prescribes the basic voltage characteristics for electricity supplied by public distribution systems for normal operating conditions. This document defines the reference values, acceptable limits, measurement intervals and monitoring periods for some typical disturbances, such as: signal frequency variations, slow voltage variations, voltage sags, temporary and transient overvoltages, short and long time voltage interruptions, the three-phase signal unbalance and the levels of high-order voltage harmonic components. A short summary of the basic requirements, prescribed by the quality standard EN 50160, is presented in Table I [5].

The system for generation and recording of PQ disturbances, which will be presented in this paper, is functionally based on the virtual instrumentation concept. The generation of three-phase signal waveforms, including the selected types of disturbances, previously defined and simulated using LabVIEW software package [6], is performed by three analog output channels of a D/A data acquisition board NI PCI 6713 [7]. The procedure for the recording of disturbances includes a USB acquisition board NI 9215A [8] and virtual instrumentation software. Real-time recording of the three-phase voltage and current waveforms is performed at the low-voltage side of the $10 / 0.4 \mathrm{kV}$ transformer station. The generated and recorded signal waveforms, including certain levels of various network disturbances, can be used in the procedures for metrological verification, checking and investigation of the measurement instruments developed for monitoring and software analysis of the basic PQ parameters.

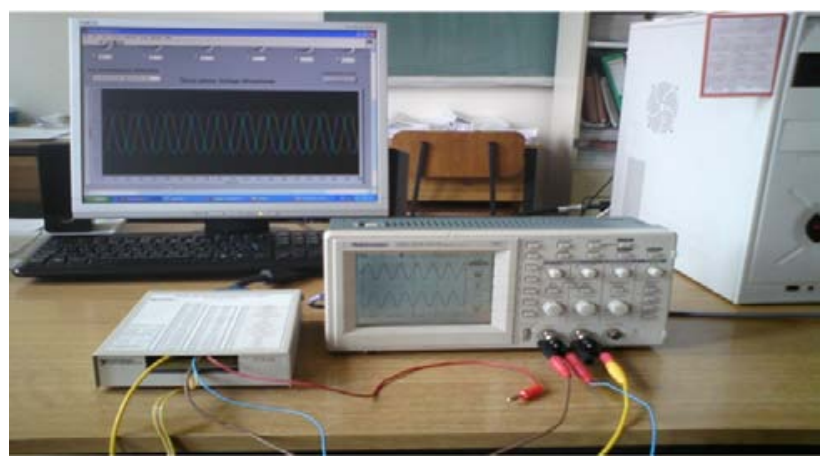

Fig. 1. System for generation of the PQ disturbances.

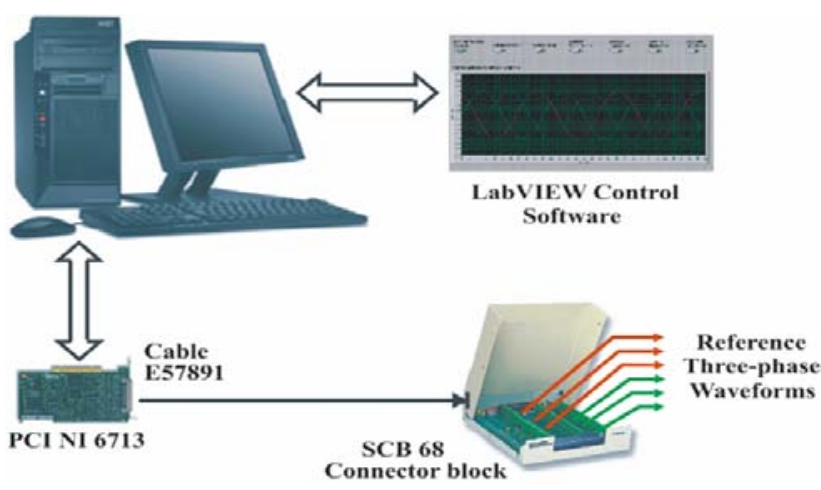

Fig. 2. Hardware configuration of the generation process.

\section{GENERATION OF POWER QUALITY DISTURBANCES}

The first segment in the development of this data acquisition system for testing and verification of PQ meters is an implementation of the procedure for software supported generation of standard disturbances. A graphical presentation and the simplified hardware block configuration of this experimental procedure are given on Fig. 1 and Fig. 2. The generation procedure includes a standard computer, supported by software applications in the LabVIEW programming environment and a data acquisition board NI PCI 6713 equipped with a connector block SCB 68.

The procedure for generation includes two connected functional segments. The first segment of this process provides the definition and selection of the reference three-phase waveforms, with specified categories for the typical disturbances of later generation. The definition of the basic parameters for different types of individual disturbances can be performed during the programming process. This is done directly using the control front panel and block diagram of the LabVIEW virtual instruments. The control front panel gives possibilities for the fast and simple correction of basic waveform parameters in accordance with some specific requirements and purposes. The second functional segment of this procedure is focused on real-time generation of the 


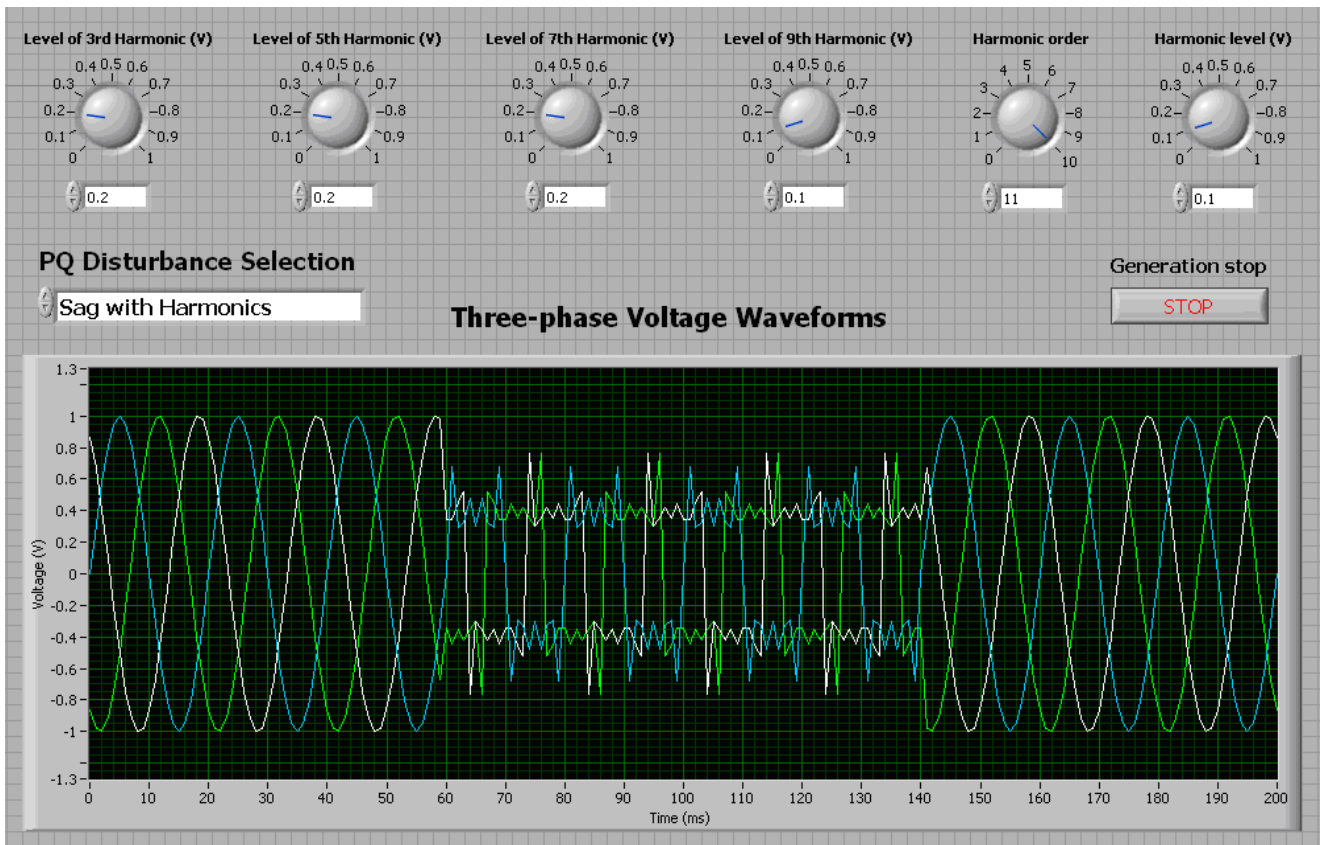

Fig. 3. Front panel of the virtual instrument for presentation of the three-phase waveforms with voltage sag and high-order harmonics.

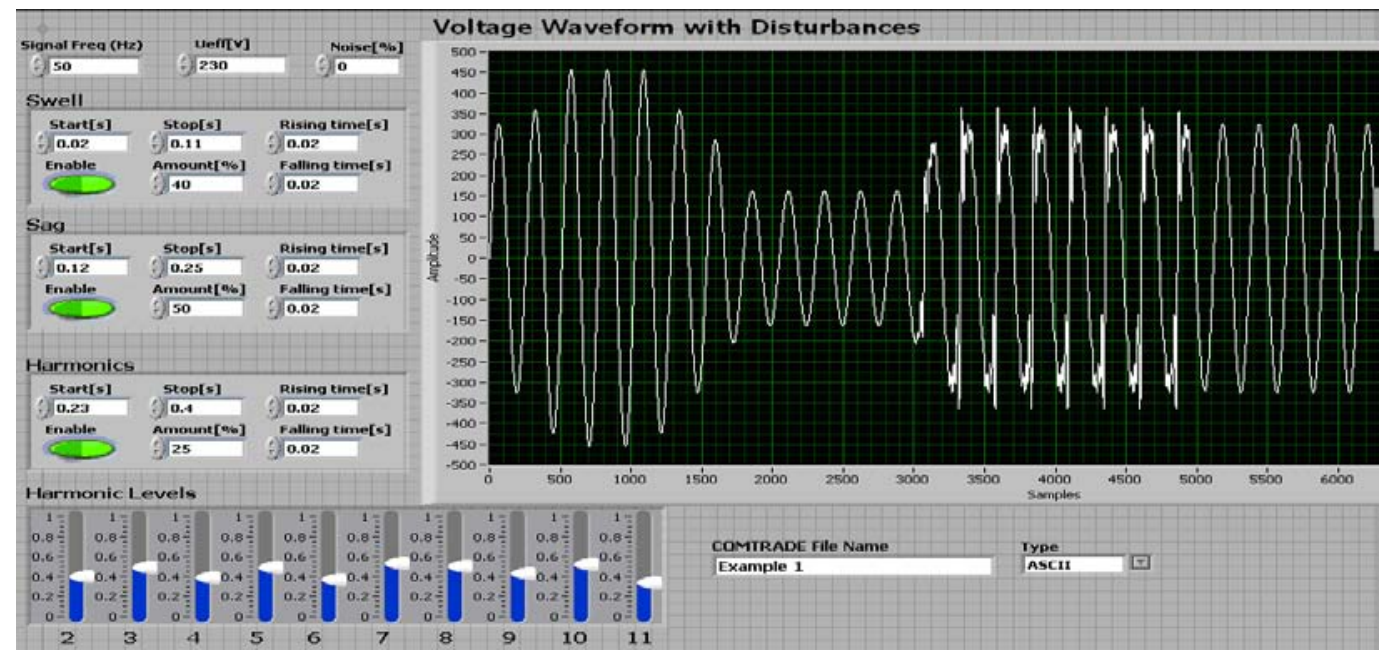

Fig. 4. LabVIEW virtual instrument for presentation of the voltage waveform with serial combination of the various signal disturbances.

previously defined and selected disturbances by means of the three analog outputs of the D/A data acquisition board NI 6713. This is an 8-channel PCI data acquisition board, capable of digital to analog input signal conversion. It is designed for a maximum output voltage range of $\pm 10 \mathrm{~V}$ and a 12-bit resolution. For this specific application three analog output channels are used. The generation process is based on the determined values of the signal samples, which were previously recorded into the acquisition board internal buffer. A very significant characteristic of this data acquisition board is the possibility of double buffering the data, which enables adding the signal sample arrays without interruption of the waveform generation process. As a result, signal samples can be continuously calculated and sent in real time to the D/A converter of the data acquisition board, which produces waveforms with different long time non-periodic disturbances [7].

This procedure provides generation of eight different categories for the disturbances: RMS voltage value variations, voltage swells, voltage sags, voltage spikes, voltage interruptions, high-order voltage harmonics, voltage swells with harmonics and voltage sags with harmonics. These categories are listed in Table II. 
TABLE II

CATEgories of THE PQ Disturbances FOR GENERATION

\begin{tabular}{||l|l||}
\hline PQ disturbances & Basic signal parameters \\
\hline RMS voltage variations & $\begin{array}{l}\text { start and stop time, } \\
\text { voltage variation level }\end{array}$ \\
\hline voltage sags & $\begin{array}{l}\text { start and stop time, } \\
\text { sag amplitude level }\end{array}$ \\
\hline voltage swells & $\begin{array}{l}\text { start and stop time, } \\
\text { swell amplitude level }\end{array}$ \\
\hline voltage spikes & $\begin{array}{l}\text { start and stop time, } \\
\text { spike amplitude level }\end{array}$ \\
\hline voltage interruption & start and stop time \\
\hline voltage harmonics & $\begin{array}{l}\text { start and stop time, } \\
\text { harmonic amplitude levels }\end{array}$ \\
\hline sag + harmonics & $\begin{array}{l}\text { start and stop time, } \\
\text { sag amplitude level, } \\
\text { harmonic amplitude levels }\end{array}$ \\
\hline swell + harmonics & $\begin{array}{l}\text { start and stop time, } \\
\text { swell amplitude level, } \\
\text { harmonic amplitude levels }\end{array}$ \\
\hline \hline
\end{tabular}

The concept of virtual instrumentation is based on standard computers, acquisition hardware components and software packages specialized for graphical presentation and software processing of the results [6]. The virtual instrument, developed in the LabVIEW environment, performs simulation and graphical presentation of the reference three-phase signal waveforms.

The control panel of the virtual instrument includes a primary switch for selection of the individual disturbance categories. In addition, the software application provides variation and adjustment of the basic signal parameters. These variations are enabled by a number of the control buttons and knobs, implemented on the front panel of the virtual instruments. The control front panel for graphical presentation of the three-phase voltage waveforms, including a combination of the voltage sag and some high-order harmonics, is presented in Fig. 3. These voltage waveforms, presented with the ten periods of the signal, are generated with a nominal standard frequency of $50 \mathrm{~Hz}$, a signal phase differences of $2 \pi / 3 \mathrm{rad}$ and a normalized amplitude level of $1 \mathrm{~V}$. The duration of the disturbance is $80 \mathrm{~ms}$, while the voltage sag amplitude level is $0.5 \mathrm{~V}$. The separated segment of the control knobs, shown on the instrument front panel, is used for the selection and adjustments of the amplitude levels in regards to the individual high-order harmonic components. The content of the individual high-order voltage harmonics can be precisely defined by a number of control knobs for the regulation of the harmonic amplitude levels, from the third order to the eleventh order of the harmonic components.

In addition to the presented example of the voltage waveforms, this procedure provides generation of the signal waveforms with serial combinations of the various signal disturbances, as illustrated in Fig. 4. For this specific case, a one-phase signal waveform is presented, including a serial combination of the voltage swell, voltage sag and specified amplitude levels of the high-order signal harmonic components, from the second to the eleventh order. For this individual disturbance category it is possible to adjust the following signal parameters: the start and stop times of the disturbances, the rising and falling times, the percentage amounts of the disturbance amplitude levels and the regulation of the individual high-order voltage harmonics.

\section{RECORDING OF POWER QUALITY DISTURBANCES}

The basic hardware configuration of the procedure for real-time recording of the voltage and current waveforms in three-phase power distribution networks, is presented in

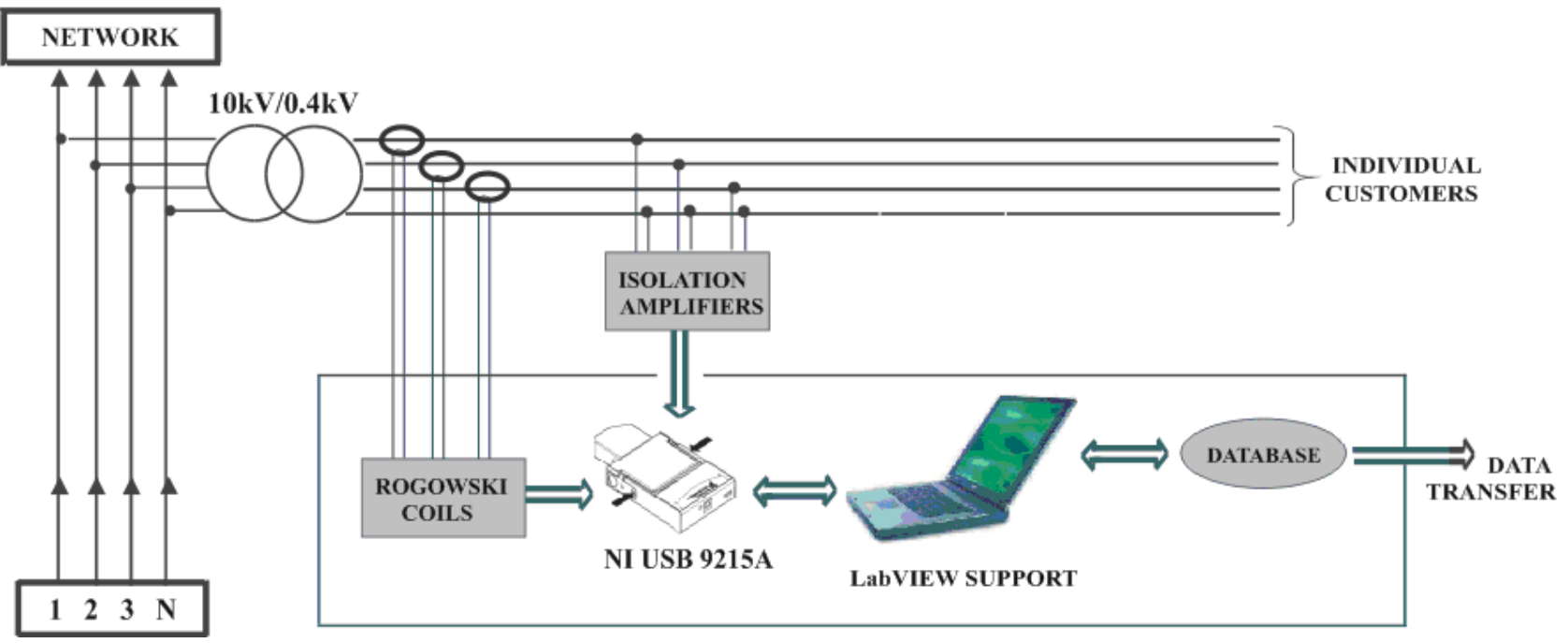

Fig. 5. Hardware configuration of the procedure for recording of the voltage and current signals in three-phase distribution networks. 


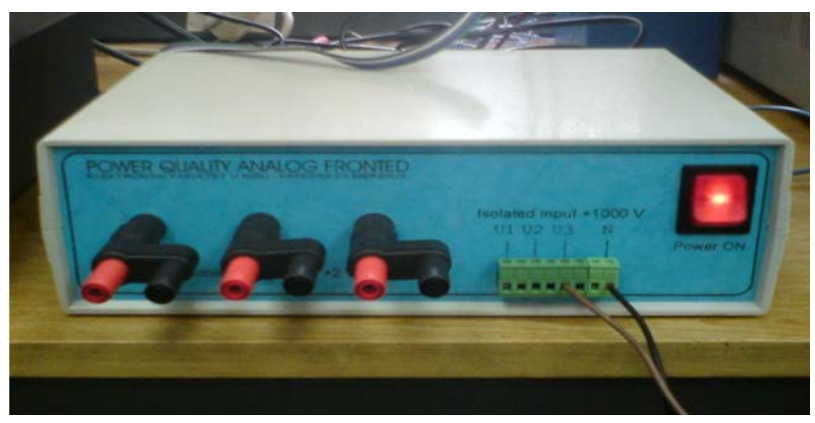

Fig. 6. Input conditioning block for voltage and current signals

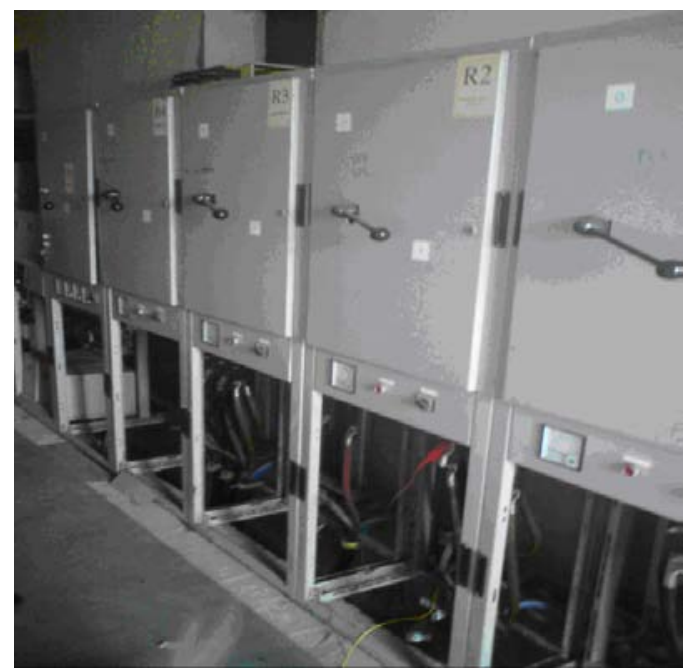

Fig. 7. Working environment in transformer station 10/0.4 $\mathrm{kV}$.

Fig. 5. This recording process includes three functionally dependent parts: the input voltage and current signal conditioning block, the USB data acquisition board NI 9215A and the control software application, developed in the LabVIEW environment. The input sensor block for the voltage and current signals is based on isolation amplifiers and Rogowski coils. The conditioning block is developed in the form of one integrated housing, as presented in Fig. 6.

The primary function of the input sensor block is receiving the voltage and current three-phase signals, including the adjustments of the signal amplitude levels to the analog inputs of the data acquisition board. The input voltage block includes three isolation amplifiers Burr-Brown ISO 122, with a linearity level of $0.02 \%$, a maximum isolation voltage value of $1.5 \mathrm{kV}$ and a possibility for performing bipolar operations within voltage range of $\pm 10 \mathrm{~V}$. In addition, in this sensor interface block three additional amplifiers are used for the outputs of the Rogowski integrators. The USB data acquisition board NI 9215A, from National Instruments, is designed with a $4 \mathrm{~A} / \mathrm{D}$ input channels, an input voltage range of $\pm 10 \mathrm{~V}$, a 16 -bit signal resolution and a maximum signal sampling rate of $100 \mathrm{ks} / \mathrm{s}$ [8]. Communication between the acquisition board and the computer is provided using a standard USB interface. The described procedure for recording the voltage and current waveforms is performed at the low-voltage side of the transformer station TS $10 / 0.4 \mathrm{kV}$. This specific transformer station is positioned inside the factory for the production of the heating elements. A graphical illustration of the working environment within this transformer station is given in Fig. 7.

The control software application designed in the LabVIEW package controls the acquisition of the voltage and current input signals, including the recording and graphical presentation of the recorded signal waveforms. Two connected parts of the control virtual instrument are developed. The first segment is related to recording the signal waveforms, while the second software segment provides a graphical presentation of the previously recorded voltage and current waveforms. The front panel of the control virtual instrument for the acquisition and recording of the signal waveforms includes a number of the control buttons and knobs for adjustments of the basic acquisition parameters, such as: the signal sampling frequency, the sampling rates, the acquisition times, the number of samples per individual channel for reading, the buffer size, the start and stop times of the recording, and the destination of the signal samples for the recording. The writing of these waveforms into a specified file locations is performed using the COMTRADE data format. The format of the recorded samples can be ASCII or BIN. The ASCII data format is not appropriate for long term signal acquisition, due to the files of the recorded waveforms being twice as large. In addition, the binary format of the files enables fast zoom and signal scrolling inside a very large record length, based on the possibility of extracting the calculate position of a particular sample inside the file. The front panel of the LabVIEW virtual instrument, designed for the graphical presentation of the previously recorded one-phase voltage and current signals, is presented in Fig. 8.

The shown virtual instrument enables the selection of the various parameters, such as: the destination of the recorded signal files, the start point for signal reading and the total number of signal reading points. The features of custom zoom and fast scrolling left and right of the waveforms are also provided. The presented waveforms include a certain level of disturbances and signal distortion, which are caused by the influences of the high-order signal harmonics. A comparative presentation of the recorded voltage and current real-time waveforms is illustrated in Fig. 9. This simultaneous graphical presentation of the recorded signal waveforms is given with a large number of signal periods. The presented current waveform clearly indicates a certain level of signal harmonic distortion, including significant periodic increases and fluctuations of the current amplitude level. 

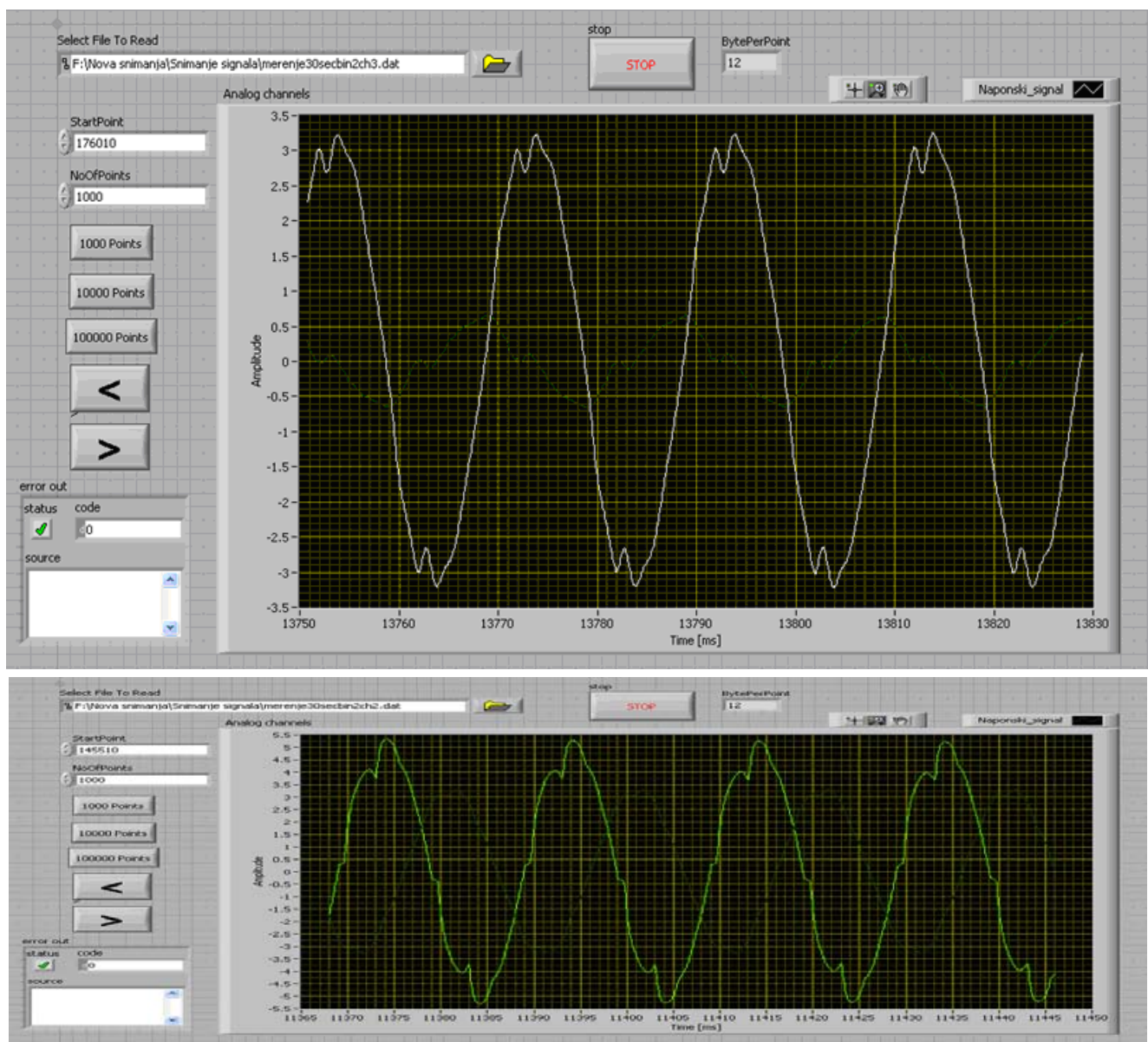

Fig. 8. Presentation of the recorded voltage (up) and current (down) waveforms disturbed in the presence of the high-order harmonics.

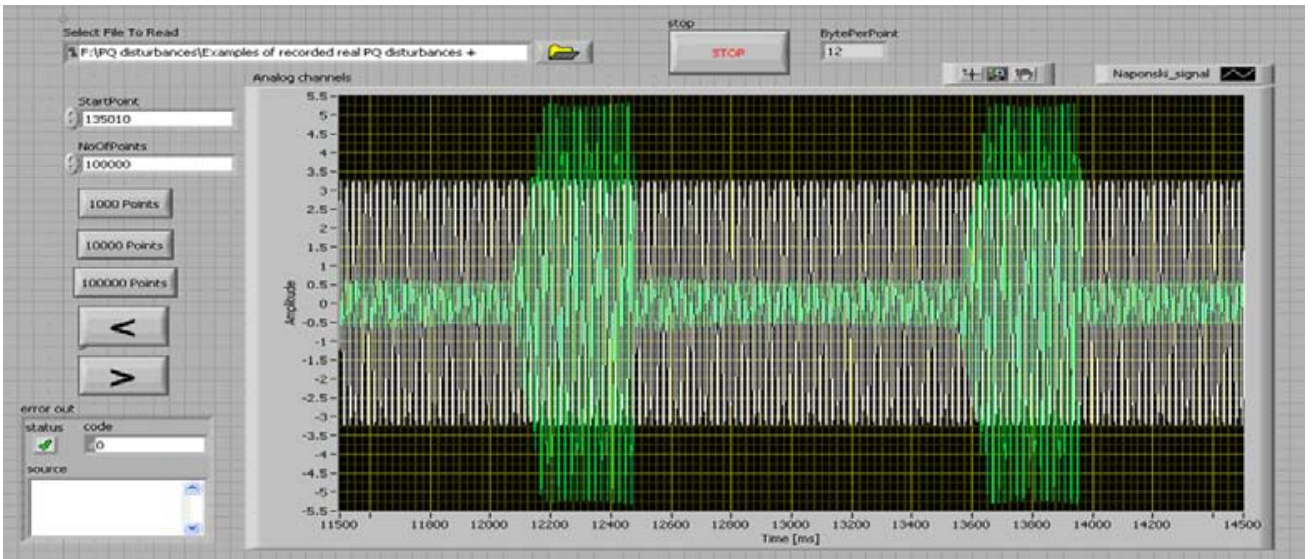

Fig. 9. LabVIEW virtual instrument for simultaneous graphical presentation of the recorded voltage and current signal waveforms.

\section{CONCLUSIONS}

Software supported procedures for the generation and recording of three-phase voltage and current waveforms, including various classes of typical PQ disturbances, are presented in this paper. The functional support of this procedures is provided by the virtual instrumentation concept, consisting of the hardware components for signal acquisition and corresponding software support. The control software application, developed in the LabVIEW environment, provides definition and variation of the basic parameters for generation, recording and presentation of the signal waveforms. The generation procedure is performed using the 
three analog output channels of a PCI data acquisition board NI 6713. Real-time recording of the voltage and current waveforms, performed at the low-voltage side of the $10 / 0.4 \mathrm{kV}$ transformer station, includes an input sensor block for signal conditioning and a USB acquisition board NI 9215A. The presented complex waveforms, generated and recorded with different categories of signal disturbances, are very useful for some specific purposes and applications, such as testing, calibration and metrological verification of the equipment for monitoring and analysis of standard PQ parameters and disturbances.

The described procedures for the generation and recording of disturbances are the first segment in the development of the DSP based instrument for the detection and analysis of standard PQ parameters and disturbances. This instrument is based on the optimal wavelet packet transform (WPT), implemented in a new algorithm for time-varying harmonic analysis of the signals in three-phase distribution networks [9]. The generated and recorded waveforms, previously illustrated in this paper, will be used for the final metrological verification and testing of the proposed optimal algorithm and the complete instrument for processing and analysis of typical network disturbances.

\section{ACKNOWLEDGMENT}

This work was supported by the Grant of the Joint European Research Project (JERP), under SEE-ERA.NET Plus Joint Call, Reference Project Number: ERA 78/01.

\section{REFERENCES}

[1] J. C. Whitaker, AC Power Systems Handbook, Third edition, Taylor \& Francis Group, LLC, New York, 2007.

[2] C. Sankaran, Power Quality, CRC Press, LLC, 2002.

[3] L. F. Auler and R. D'Amore, "Power quality monitoring controlled through low-cost modules," IEEE Trans. Instrum. Meas., Vol. 58, No. 3, pp. 557-562, Mar. 2009.

[4] D. Gallo, C. Landi, and N. Rignano, "Real-time digital multifunction instrument for power quality integrated indexes measurement," IEEE Trans. Instrum. Meas., Vol. 57, No. 12, pp. 2769-2776, Dec. 2008.

[5] Power quality application guide, Voltage disturbances, Standard EN50160, Copper Development Association, 2004.

[6] LabVIEW user manual, National Instruments Corporation, www.ni.com, 2007.

[7] NI PCI 6713 data acquisition board, User guide and specifications, National Instruments Corporation, 2005.

[8] NI USB 9215A data acquisition board, User guide and specifications, National Instruments Corporation, 2007.

[9] M. E. Salem, A. Mohamed, S. A. Samad, "Power quality disturbance detection using DSP based continuous wavelet transform,” Journal of Applied Sciences, Vol. 7, No. 6, pp. 893-902, 2007.

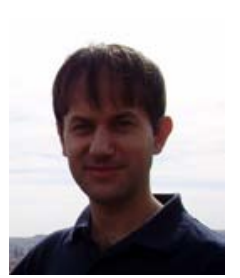

Milan Simic was born in Kragujevac, Serbia, in 1977. He received his M.S. in Technical Sciences, in the scientific field of Measurement, from the University of Nis, Faculty of Electronic Engineering,, Serbia, in 2008. Currently he is working as Teaching and Researching Assistant in the Department of Measurement, University of Nis, Serbia. His current scientific and research interests include measurement science and technology, power quality and utilization techniques, digital signal processing techniques, intelligent measurement systems and virtual instrumentation.

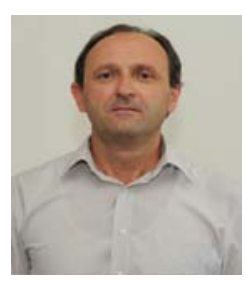

Dragan Denic was born in Vlase, Vranje, Serbia, in 1963. He graduated from the University of Nis, Faculty of Electronic Engineering, in field of Measurement Automatization, in May 1988. He received his M.S. and Ph.D. in Electrical Science from the University of Nis, Serbia, in 1992 and 1996, respectively. He is currently a Full Professor in the Department of Measurement, University of Nis, Serbia. He has actively participated in many science and research projects for the Ministry of Science and Technological Development and in many significant projects for industry. He is author or coauthor of more than 50 papers published in international journals or conference proceedings. As an expert, he was involved for more than 3 years as independent consultant for GPI (Gurley Precision Instruments), a leading company in his field of research. His current research interests include measurement science, position measurement, telemetry, and computer based measurement systems.

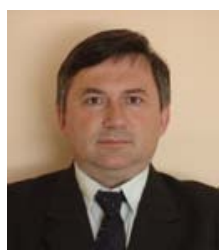

Dragan Zivanovic was born in Nis, Serbia, in 1965. He received his Ph.D. in Technical Sciences, in the field of Measurement from the University of Nis, Faculty of Electronic Engineering, in 2006. He is currently a Docent (Assistant Professor) in the Department of Measurement, University of Nis, Serbia. He has obtained twenty years of experience in research and new product development in the areas of embedded systems, real time software, digital instrumentation, smart transducers, industrial sensor applications, data acquisition and virtual instruments.

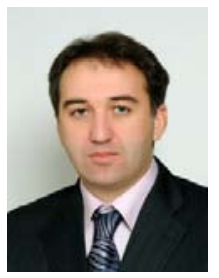

Dimitar Taskovski received his Ph.D. in Electrical Engineering from the University Ss Cyril and Methodius in Skopje, Macedonia, in 2004. He is currently an Associate Professor in the Faculty of Electrical Engineering and Information Technology at that university. His current research interests include signal and image processing, wavelets and filter banks, data hiding and watermanking, and power quality. 


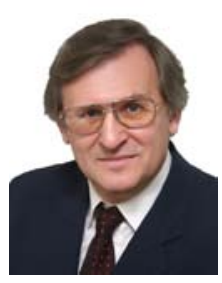

Vladimir Dimcev obtained his B.S. in Electrical Engineering as well as his M.S. and Ph.D. from the University Ss. Cyril and Methodius in Skopje, Macedonia, in 1983, 1990 and 2001, respectively. Since March 1987, he has been employed by the Faculty of Electrical Engineering and Information Technologies, Department for Electrical Measurements, University Ss. Cyril and Methodius in Skopje. He started out as a Teaching and Research Assistant. In 2003 he was promoted to Assistant Professor and in 2007 he was promoted to Associate Professor. His scientific and research interest include power system measurements and instrumentation, earthing and measurement of grounding grid parameters, electromagnetic interference, data acquisition systems, and power quality in electrical systems. He is a Senior Member of the IEEE and served as President of the IEEE Macedonia section from 2006-09. 